\title{
Узкополосный линейно-поляризованный эрбиевый волоконный лазер с самосканированием длины волны вблизи 1.6 мкм
}

\author{
$\underline{\text { Е.К. Каширина }}^{1,2, *}$, И.А. Лобач ${ }^{1}$, С.И. Каблуков ${ }^{1}$ \\ ${ }^{1}$ Институт автоматики и электрометрии СО РАН \\ ${ }^{2}$ Новосибирский государственный технический университет \\ *E-mail: kashirinae.konst@gmail.com
}

DOI: 10.31868/RFL2020.59-60

Лазеры с самосканирование длины волны представляют подвид перестраиваемых лазеров, в которых перестройка происходит спонтанно за счет внутренних процессов без использования специальных управляемых извне селективных элементов. Явление самосканирования было обнаружено ещё на заре лазерной эпохи при исследовании рубиновых лазеров, однако оно не привело к появлению как-либо практических применений из-за малой ширины контура усиления в рубиновых лазерах. С обнаружением этого явления в волоконных лазерах, в которых ширина контура усиления достигает десятков нанометров, интерес к исследованию таких лазеров возобновился. Например, в иттербиевом [1] и тулиевом [2] лазерах ширина области самосканирования превысила 20 нм. Среди всех волоконных лазеров особый интерес вызывают эрбиевые лазеры, которые работают в области минимума потерь кварцевых волокон. По этой причине, на протяжении многих лет такие лазеры служили мотором развития волоконной оптики. При получении самосканирования длины волны в эрбиевых лазерах исследователи столкнулись с существенными трудностями. В единственной конфигурации эрбиевого лазера с самосканированием длины волны, реализованной до настоящего времени [3], авторам для получения эффекта пришлось добавить отрезок тулиевого волокна. При этом диапазон сканирования не превышал $0.5 \mathrm{Hм}$, а область сканирования выбиралась путем перестройки дополнительного внутрирезонаторного фильтра от 1.54 до 1.57 мкм.
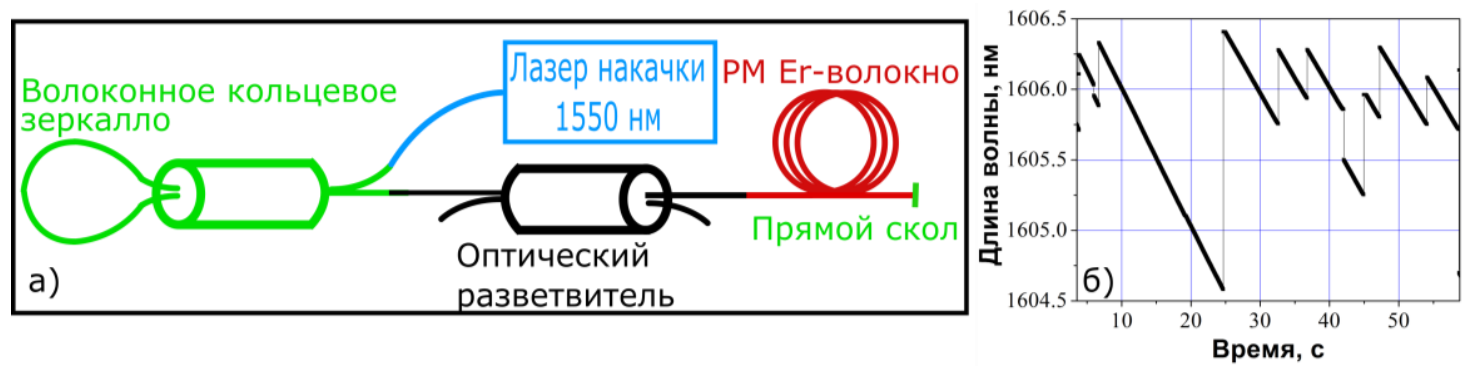

Рис. 1. Схема волоконного Еr-лазера с самосканированием частоты (а) и зависимость длины волны от времени (б).

В настоящей работе мы впервые продемонстрировали самосканирующий эрбиевый волоконный лазер в стандартной конфигурации (Рис. 1а), в которой не используется дополнительных активных волокон. Активной средой лазера было высоколегированное Er-волокно с одинарной оболочкой IFX-EDF-HD-PM (iXblue photonics) длиной $11 \mathrm{~m}$, с поглощением в максимуме на длине волны 1530 нм >3 дБ/м. Накачка осуществлялась в край полосы поглощения другим непрерывным эрбиевым лазером с длиной волны генерации 1550 нм и линейной поляризацией излучения через волоконное кольцевое зеркало на основе спектральноселективного разветвителя 1550/1790. Последний элемент также выполнял роль 
плотного зеркала для излучения генерации. Вторым зеркалом резонатора выступал торец, сколотого под прямым углом, активного волокна. Дополнительный волоконный разветвитель 95/5 использовался для измерения параметров генерируемого излучения. Все элементы были выполнены из волокна с сохранением поляризации.
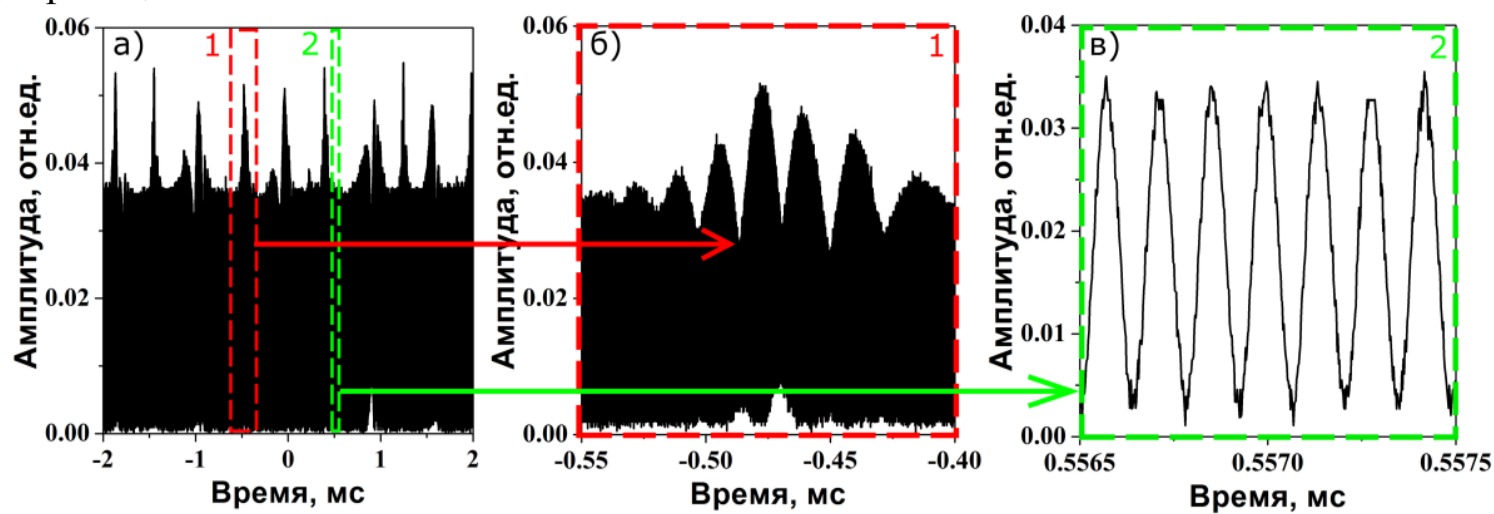

Рис. 2. Временная динамика интенсивности на разных масштабах времени.

Было установлено, что лазер генерирует излучение вблизи длины волны 1606 нм с диапазоном сканирования около 1 нм и скоростью $\sim 0.1 \mathrm{Hм} /$ сек (Рис. 1б). При этом наблюдался режим обратного сканирования, в котором длина волны уменьшается во времени. Пороговая мощность накачки на входе в активное волокно составила $\sim 800$ мВт, а выходная мощность генерации $\sim 25$ мВт. Отличительной особенностью данного лазера является временная динамика интенсивности, представленная на Рис. 2. Вместо генерируемых в других лазерах с самосканированием длины волны импульсов [1,2] наблюдается квазинепрерывная генерация с периодическими всплесками интенсивности (Рис. 2б). Период следования всплесков $\sim 2$ кГц. В промежутках между такими всплесками интенсивность излучения изменяется по гармоническому закону (Рис. 2в). Данная зависимость интенсивности от времени, а так же Фурье-анализ показывают, что лазер генерирует преимущественно две соседние продольные моды с расстояниями 7.1 МГц, что соответствует длине резонатора 14.5 м. Можно предположить, что во время очередного всплеска происходит смена низкочастотной компоненты спектра на соседнюю более высокочастотную. Такое периодическое изменение частоты генерации проявляется в виде эффекта самосканирования.

Также было изучено состояние поляризации генерируемого излучения при помощи делителя поляризации. Оказалось, что, несмотря на отсутствие поляризующих элементов в схеме, выходное излучение имеет линейную поляризацию (дискриминация второй поляризационной моды составила $\sim 17 \mathrm{~dB}$ ), что может быть связано с линейной поляризацией излучения лазера накачки.

Подробное описание экспериментов и полученных результатов будет представлено в докладе.

Исследование выполнено в рамках гранта Российского научного фонда (проект № 18-12-00243)

\section{Литература}

[1] I. A. Lobach, A. Yu. Tkachenko et al, Laser Phys. Lett. 13, 1-7 (2016)

[2] A. E. Budarnykh, A. D. Vladimirskaya et al, Opt. Lett. 43, 5307-5310 (2018)

[3] P. Navratil, P. Peterkaa et al, Opto-Electronics Review 26, 29-34 (2018) 